https://helda.helsinki.fi

\title{
Loneliness in assisted living facilities : An exploration of the group process
}

\section{Jansson, Anu}

2021-07-04

Jansson , A , Karisto , A \& Pitkälä , K 2021 , ' Loneliness in assisted living facilities : An

exploration of the group process ' , Scandinavian Journal of Occupational Therapy , vol. 28 , no. 5 , pp. 354-365 . https://doi.org/10.1080/11038128.2019.1690043

http://hdl.handle.net/10138/333035

https://doi.org/10.1080/11038128.2019.1690043

unspecified

acceptedVersion

Downloaded from Helda, University of Helsinki institutional repository.

This is an electronic reprint of the original article.

This reprint may differ from the original in pagination and typographic detail.

Please cite the original version. 
Title page

\section{Loneliness in assisted living facilities: an exploration of the group process}

\section{ANU JANSSON ${ }^{1}$, ANTTI KARISTO ${ }^{2}$, KAISU PITKÄLÄ ${ }^{1}$,}

1) University of Helsinki, Department of General Practice and Helsinki University Hospital, Unit of Primary Health Care, PO Box 20, 00014 University of Helsinki, Finland.

2) Faculty of Social Sciences, Social and Public Policy, University of Helsinki, Finland, PO Box 54, 00014 University of Helsinki, Finland.

Corresponding author Jansson Anu: University of Helsinki, Department of General Practice and Helsinki University Hospital, Unit of Primary Health Care, PO Box 20, 00014 University of Helsinki, Finland. anu.jansson@vtkl.fi 


\begin{abstract}
Background. More than one in three older people in assisted living facilities suffer from loneliness that leads to adverse health outcomes. Group work may have the potential to improve residents' quality of life.
\end{abstract}

Aims/Objectives. The purpose of this feasibility study was to thoroughly describe a facilitated group process and compare its effects on cognitively impaired $(n=6)$ and cognitively intact $(\mathrm{n}=7)$ lonely resident groups in assisted living facilities.

Material and Methods. We used a closed, occupational therapy-oriented group model designed for lonely people. The study used a qualitative, multi-method approach. Material included individual and focus group interviews, observations and the facilitators' field diaries.

Results. Loneliness was reflected in diverse ways in both groups. Meaningful activities in mutual interaction played an important role in empowering the participants and enabling the development of the group process. Group processes had similar, parallel steps, from which the participants seemed to benefit. Surprisingly, the cognitively impaired group progressed towards self-direction more quickly than the cognitively intact group.

Conclusions. A group process with clearly progressing steps revealed that lonely older people are capable of empowerment and self-direction - despite their frailty and cognitive impairment. Facilitators should be familiar with group processes to enable them to progress effectively.

Keywords: loneliness, group work, group process, cognitive impairment, facilitator, assisted living facilities 


\section{Introduction}

Moving from a private home to a long-term care environment may be a stressful life event for an older person [1]. Social networks may shrink and the quality of life may decline [2]. According to some studies, older people who live in care homes are surprisingly vulnerable to loneliness [1,3-4]. Although they may feel safe, they may also feel lonely [3,5]. More than one in three residents in assisted living facilities may suffer from loneliness [6-8]. Adverse health outcomes [9-12], even a higher mortality risk [13-14] are well known. Thus, older people's loneliness should be addressed, and means should be developed for alleviating it. However, surprisingly few studies of loneliness have been conducted in long-term care settings [1]. An assisted living facility is an interesting environment in which to examine loneliness, as it is somewhere between home and an institution [5,15]. People live there with support, care and activities, but their existing social surroundings and everyday life do not necessarily meet their expectations [2,5].

Group work can potentially improve residents' quality of life in institutional settings by enhancing meaningful social interaction [1] and mutual peer support [4,16-18]. Connectedness with other residents has been considered an important prerequisite for a good life, thus, a lack of contact with peer residents may lead to loneliness and poor quality of life [5,17]. Group work is quite a commonly used method among older people [19-20]. In longterm care facilities, various forms of group work have been available, from unstructured and activity groups to closed groups for specific targets and support groups [21].

Already in the 1960s, Lowy [22] suggested that primary groups may alleviate loneliness and help in coping with losses. Maizler \& Solomon [23] noted that the pain of social isolation, i.e. loneliness, may be a motivator for group attendance in institutional settings. Residents who 
are 'in the same boat' in terms of their life experiences may provide each other with understanding and support during the changes and losses in their social relationships [21]. This social identity may be an important component in effective interventions targeting loneliness [24]. However, Cohen-Mansfield and Perach [25] found only one face-to-face group intervention in assisted living facilities in their critical review of 22 interventions for alleviating loneliness. This intervention was based on facilitating social interaction and cognitive stimulation in a cognitive enhancement group programme [26].

Therefore, our study conducted in assisted living facilities may have some novelty value: we scrutinised a closed group process among lonely residents. The 'Circle of Friends' group model that we chose for the study was originally designed for community-living lonely older people [20,27-28]. A randomised controlled trial found it to be effective in improving older people's quality of life, health and cognition [29]. Moreover, it was also beneficial among people with cognitive decline [30]. This group model has been disseminated widely in Finland and has had more than 10000 participants [28,31]. Its potential to increase connectedness and friendships is strong [20].

Our aim was to learn how a model originally designed for community-living people works in assisted living facilities. We were also interested in whether the model was feasible among cognitively impaired residents who are increasingly frequent in these facilities, and have specific care and support needs [32]. Some evidence shows that older people with mild or moderate cognitive impairment are able to participate in group meetings [19], in which they are able to share their experiences [30,33]. The Finnish trial showed that group work postponed cognitive decline among people with mild to moderate dementia [30]. Therefore, group work may provide a beneficial means to intervene in loneliness and to improve quality of life in assisted living, and is worth exploring [34] . 


\section{Aim of the study}

In this feasibility study we thoroughly explored a facilitated occupational therapy-oriented group process, based on "Circle of Friends" group model, in the context of assisted living facilities. We compared how the process proceeded in two groups: one with cognitively impaired residents, the other with cognitively intact lonely residents. Our detailed description of the closed group process may enable novel, important information for those who apply group interventions for loneliness in institutional settings.

\section{Materials and methods}

\section{Participants and their living environment}

After the Helsinki University Hospital ethics committee and respective committee of the City of Helsinki approved the study protocol, we recruited two groups from two assisted living facilities operated by the City of Helsinki. One group consisted of six people with mild or moderate cognitive impairment (Mini-Mental State Examination was 15-24) [35]. Difficulties with episodic memory and executive function as well as poor time and place orientation were typical characteristics of the participants in the cognitive impairment group. The other group, in turn, consisted of seven cognitively intact people, whose Mini-Mental State Examination score was $25-30$. These participants were very frail and had multimorbidities; mobility problems in particular. The main inclusion criteria were that they experienced loneliness at least sometimes and volunteered to participate in the group. Their experience of loneliness was elicited by a written questionnaire, asking 'Do you suffer from loneliness?' (seldom or never/sometimes/often or always). This question has proven to be easy for older people to understand and answer $[5,13,36]$. Using the questionnaire, we also gathered background information on the participants: age, marital status and education. We also inquired about their expectations of the group intervention. Table 1 shows the participants' characteristics. 
Table 1. Characteristics of the participants

\begin{tabular}{|c|c|c|}
\hline Characteristics of participants & $\begin{array}{l}\text { Cognitively intact } \\
\text { group }(n=7)\end{array}$ & $\begin{array}{l}\text { Cognitively impaired } \\
\text { group }(n=6)\end{array}$ \\
\hline Women & 7 & 4 \\
\hline Men & 0 & 2 \\
\hline Age, mean (range, yrs.) & $80(72-87)$ & $88(82-94)$ \\
\hline Widowed & 4 & 2 \\
\hline At least high school education & 3 & 0 \\
\hline \multicolumn{3}{|l|}{ Living in } \\
\hline -apartment & 7 & 4 \\
\hline -group home & 0 & 2 \\
\hline \multicolumn{3}{|l|}{ Loneliness experienced } \\
\hline -sometimes & 5 & 6 \\
\hline -often or always & 2 & 0 \\
\hline MMSE, mean (range) & $28(25-30)$ & $20(15-23)$ \\
\hline Mobility devices & 5 & 4 \\
\hline \multicolumn{3}{|c|}{ Expectations of the group intervention } \\
\hline -alleviation of loneliness & 5 & 3 \\
\hline -making friends & 5 & 2 \\
\hline -peer support & 6 & 3 \\
\hline -more contentment with life & 6 & 4 \\
\hline
\end{tabular}

The study participants lived in assisted living facilities where housekeeping, meals-on-wheels and 24-hour personal assistance were available. The cognitively intact people lived in their own single apartments with a kitchenette and bathroom and the same support available. Some cognitively impaired residents lived in group homes with their own private room. The participants, like all the other residents, could use common rooms such as clubrooms, a gym, the dining room, and a hobby room, as well as the TV lounges in the corridors. In both houses, the staff included a manager, specialised and assistant nurses, a physiotherapist, an occupational therapist, social instructors, and assisting staff. Both facilities had a weekly 
social programme, involving music and facilitated games, but this was somewhat more active in the facility in which the cognitive impaired residents lived [5].

\section{Group model and role of facilitators}

The Circle of Friends group intervention has previously shown to be effective and feasible among lonely older people [29]. The group model has been developed and disseminated over 17 years for older people living at home. After establishing the effectiveness and wide dissemination, the focus of our interest shifted towards different context, where loneliness is a major harm. At this stage we wanted to explore the group model in assisted living facilities among frail older adults and people with cognitive impairment to further assist and monitor the intervention process. With a qualitative approach a participant involvement allows for a range of experiences to be mapped and to learn from. This way we aim to follow the guidance of "Developing and evaluating complex interventions" by Medical Research Council. [37]. In the assisted living facilities, we adopted its original structure: a facilitated, closed group with six to eight participants (all suffering from loneliness), who met with their peers 12 times, once a week, for three months [28]. In this context a closed group means that new members are not recruited after the intervention has started, and that the facilitation has a clear beginning and end [38]. Two group facilitators help the group make progress and find their own solutions to loneliness, from group formation to an efficient and active phase, and finally a self-directed phase. Over 60 per cent of the community-living participants continued to meet on their own after the official facilitated group meetings ended [28]. The group process was originally inspired by Tuckman's [39] therapy group development stages.

The role of the facilitators is important, and a common training background is essential [28]. All facilitators were social and health care professionals: a geriatric nurse, social worker and social gerontologist. They had undergone Circle of Friends training, the trainers of which 
were occupational therapists. In the training they learned the same working methods, which form an important prerequisite for a successful intervention $[28,40]$. We recruited the facilitators for this study from outside the staff of the assisted living facilities in order to guarantee neutrality when working with the study participants. Trained group facilitators worked in the same pairs in the groups. The main aim of the facilitators in both groups was to help the participants reflect on and alleviate their experiences of loneliness as well as to promote meaningful occupations, interaction and peer support within the group.

The facilitators aimed to implement the group meeting according to the Circle of Friends group model [28] and the four development phases: planning, beginning, middle and ending [38]. Group planning starts well before the first group meeting, when composing the group and interviewing the participants. The group process normally begins with the participants' introductions and by creating common goals, a structure and contract for the meeting. Encouraging the group participants to express their experiences of loneliness is also important. The facilitators fine-tune their work in the middle phase using a cycle of assessment, intervention and reassessment as the group process develops. The main idea is to facilitate group functioning, interaction and help the participants achieve their own goals. In the last phase, the facilitators help the participants conclude the group process. They support self-direction and develop the participants' own empowering leadership. Throughout the process, the group facilitators must pay careful attention to goals, group dynamics, the contract, and promote cohesion [38]. The facilitators' final goal is to gradually become unnecessary.

\section{Data collection and analysis}

The data were collected over six months from three perspectives: that of the facilitators, the observer (first author AJ) and the participants. 
The group facilitators wrote an individual field diary after every group meeting. This material consisted of the objectives, content and phenomena as well as descriptions of the participants' behaviour and interactions in each group meeting. The facilitators also reflected on their own role in their diaries [27]. Precise instructions were given for writing the diaries, and these were followed consistently. However, an individual writing style was allowed, and the facilitators left their own personal stamp in their diaries. For example, one of the facilitators reflected on the group phenomena very carefully, with many details, whereas another reflected more on her own emotions than of those of the others.

The observation took place when the group process began. AJ observed both groups during the two-hour group meetings on three different occasions: in the initial phase, middle phase, and during the last meeting of the three-month group process. Observations focused on the interaction between the participants, the facilitators' work and the development of the group process. The two-hour group discussions of both groups were recorded during these three meetings.

As stated earlier, a written questionnaire before the group process surveyed the residents' loneliness, demographic variables and their expectations of the meetings. Two weeks after the group process, a second written questionnaire surveyed the residents' experiences of taking part in the group. To deepen the topics of the written questionnaires, we also individually interviewed the participants, flexibly using a semi-structured thematic guide before and after the three-month group process. The interviews before the group meeting focused on the participants' interests, their own expectations of the intervention and their experiences of loneliness $[5,21,27-28,41]$. The individual interviews after the group process focused on the experiences of the group. The interviews varied from half an hour to one and a half hours. Two focus group interviews, lasting one hour and 40 minutes, were conducted at the end of the data collection procedure after the facilitated group process, separately for the cognitively 
intact and the cognitively impaired group. The purpose of these was to focus on the group participants' shared view of loneliness and their participation in the group meetings.

The data produced altogether 69 field diary pages and 810 transcribed pages (Times New Roman 12, single spacing), which in turn consisted of 26 individual participant interviews, two focus group interviews, and six observed and recorded group meetings. The participants' experiences of loneliness, as well as of the Circle of Friends group model, are reported in detail elsewhere [5,28].

To explore the group process, we began by reading the facilitators' diaries several times, separating the diaries of the facilitators of the cognitively impaired group from those of the cognitively intact group. The first reading was when the researchers received the diaries after each group meeting [27]. The second and the third readings were just before the middle and last phase of the group observation, to obtain an overall picture of the group process so far. The fourth reading was when the diaries were analysed.

We identified and mapped out all the units and data blocks that related to the common essential meaning in the diaries [42]. We grouped these meaning units manually. For example, in the cognitively impaired group, in the second group meeting, four data blocks were related to the group formation, one to trust and encouragement, and two described conflicts. Leaning on abductive reasoning and finding clues in the data as well as in the literature on group work, we grouped these meaning units into stages [27].

This was a complex intervention in which it was important to explore how this originally successful group model worked in different contexts and how its implementation varied [43]. These stages were compared to Toseland's [38] and Tuckman's [39] group development and to the typical group progress of the Circle of Friends [27-28]. Then, we began to identify the observations that either supported or did not support these initial group processes. We did this 
carefully, using different data sources (data triangulation) from the diaries, observations, individual- and focus group interviews. Finally, we compared the differences between the two framed group processes, including the participants' experiences and the observations of the cognitively impaired and cognitively intact group.

\section{Results}

In the following, we carefully describe the processes of the two groups. In order to deepen the meanings of the group process and to illustrate how the findings are connected to prior literature findings at each stage of the group process, we combine the results with the literature.

Table 2 summarises the group stages and their progression and indicates timing similarities and differences between the group processes. All in all, both groups went through the same stages. However, the cognitively impaired group progressed slightly faster through the stages. 


\begin{tabular}{|c|c|c|c|c|c|c|c|c|c|c|c|c|c|c|}
\hline \multirow{2}{*}{$\begin{array}{l}\text { GROUP } \\
\text { STAGE }\end{array}$} & \multicolumn{14}{|c|}{ GROUP SESSIONS } \\
\hline & Interview & 1 & 2 & 3 & 4 & 5 & 6 & 7 & 8 & 9 & 10 & 11 & 12 & $\begin{array}{c}\text { Independent } \\
\text { meetings }\end{array}$ \\
\hline Expectations & $x \circ P P$ & $\begin{array}{c}x 0 \\
\mathbb{I P}\end{array}$ & & & & & & & & & & & & \\
\hline $\begin{array}{l}\text { Introduction, role } \\
\text { searching }\end{array}$ & $x \circ \mathbb{P}$ & $\begin{array}{l}x 0 \\
\mathbb{I P}\end{array}$ & & & & & & & & & & & & \\
\hline Group formation & & oIP & $\begin{array}{l}\text { xo } \\
\mathbb{P}\end{array}$ & $x \mathbb{P}$ & & & & & & & & & & \\
\hline $\begin{array}{l}\text { Finding and } \\
\text { naming the team } \\
\text { spirit }\end{array}$ & & $\begin{array}{l}X 0 \\
\mathbb{P}\end{array}$ & $\begin{array}{l}x 0 \\
\mathbb{P}\end{array}$ & & & & & & & & & & & \\
\hline $\begin{array}{l}\text { Starting to trust } \\
\text { each other }\end{array}$ & & & $\begin{array}{l}x \mathrm{MP} \\
0 \mathbb{P}\end{array}$ & o MP & $\begin{array}{l}x 0 \\
M P\end{array}$ & $x$ MP & & & & x MP & & & & \\
\hline Minor conflicts & & & $x \mathbb{P}$ & & $\begin{array}{l}x \mathbb{P} \\
\text { o MP }\end{array}$ & $\begin{array}{l}\text { x } 0 \\
\text { MP }\end{array}$ & $\begin{array}{l}\mathrm{x} 0 \\
\mathrm{MP}\end{array}$ & x MP & o MP & o IP & & & & \\
\hline Getting tired & & $x \mid P$ & & $x \mathbb{P}$ & & & & $\begin{array}{l}x 0 \\
M P\end{array}$ & & & & & & \\
\hline $\begin{array}{l}\text { Achieving goals, } \\
\text { effectively } \\
\text { working group }\end{array}$ & & & & o IP & $x M P$ & O MP & $\begin{array}{l}\mathrm{x} 0 \\
\mathrm{MP}\end{array}$ & o MP & $x \mathrm{MP}$ & $x F P$ & $\begin{array}{l}\text { Xo } \\
\mathrm{FP}\end{array}$ & $x F P$ & $x F P$ & \\
\hline $\begin{array}{l}\text { Self-directed } \\
\text { group }\end{array}$ & & & & & & & & $x F P$ & o FP & $x F P$ & o FP & $\begin{array}{l}x \text { MPP } \\
\text { o FP }\end{array}$ & o FP & \\
\hline Future plans & & & & & & & & & & & $x F P$ & o FP & $\begin{array}{l}\text { X } 0 \\
\text { FP }\end{array}$ & \\
\hline $\begin{array}{l}\text { Preparing for } \\
\text { an independent } \\
\text { group, excitement }\end{array}$ & & & & & & & & & & & $x F P$ & o FP & o FP & $\times 0$ \\
\hline
\end{tabular}

Table 2. Development of group processes and role of facilitators in phases. The group of cognitively impaired residents is described using $\mathbf{x}$ and the cognitively intact residents using o. $\mathrm{PP}=\mathrm{Planning}$ phase (facilitator-led), $\mathrm{IP}=$ Initial phase (plenty of facilitation), $\mathrm{MP}=$ Middle phase (withdrawn facilitation), $\mathrm{FP}=$ Final phase (low facilitation)

\section{The interview initiates the group process}

Before the group process began, many participants responded in the questionnaire that they expected alleviation of loneliness, new friendships and peer support from the group meetings. In the individual interviews, the expectations were diverse in both groups, but in the cognitively intact group in particular they were even abstract and metaphorical: 'I expect a prince to come on a white horse and find me'. The participants expressed a total of 22 expectations. Most of these related to connectedness: interaction with others, alleviation of loneliness and sense of connection: 'It would be nice if there was someone like me in the group'. Some of them also stressed the importance of the group and at the same time 
criticised the fact that there had been no such previous meetings: 'When loneliness strikes, where I can go? Nowhere. There should be some kind of space where you can sit with others at an agreed time'. Five of the named expectations where related to their own interests and one to the group process: 'I expect the facilitators to take the group process into account in the group'.

The cognitively impaired participants expressed a total of nine expectations of the group meetings. Three of them were related to interaction with others and the rest were suggestions regarding the contents of the group meetings, such as 'Music would be nice'. In the interviews, many of both groups' participants returned to the objectives and purpose of the group meetings. They asked themselves aloud, 'Why am I going to participate in this group?' and 'What are we meant to do there'. This is similar to the findings of Evans, Chisholm and Walshe [44] during the first group meeting in their psychodynamic group intervention for older people in a day hospital. The participants also expressed uncertainty: 'Maybe I'm a little bit shy, I don't really dare participate. I don't think I can do the right things in the group'.

The interviews had the function of orienting and getting the participants ready, familiarising them with the group process and making them feel that someone was taking their expectations seriously [38]. To many participants, the interviews resembled a negotiation. They wondered aloud what the group might mean to them, what excited them and what they would get from it. The interview played an essential role in smoothing out and clarifying the start of the group process.

\section{Group cohesion begins to develop in the initial phase}

The participants' experiences of loneliness formed the basis of homogeneity, which is important in a group [19]. Those with similar life situations usually wish to share their 
experiences, which helps them work together and identify a common purpose for the group meetings [38]. The participants also raised the importance of similarity: 'I hope we're all somehow similar and can experience things in the same way. It may expand our own thinking'. Reflecting on and venting experiences of loneliness with peers may help people notice that they are not alone with their experiences [38].

The first group meeting began with the participants introducing themselves to each other. Introduction is a necessary part in order to start the social interaction in the group [38]. It was particularly important because most of the participants did not know each other. Only two cognitively impaired participants had met incidentally in the gym. In the cognitively intact group, three of the participants had met earlier at a garden party but had not spoken to each other since.

In the group with cognitive impairment, the facilitators used an old teddy bear to mediate introduction as an 'ice breaker'. In the cognitively intact group, art pictures were used: participants chose a picture and used it to introduce themselves [45]. In the cognitively impaired group, the participants talked about themselves using verbally shorter terms. The facilitators needed to support them more than those in the cognitively intact group, and gently led the participants back to the point [46] without making them feel embarrassed or incompetent [19]. They also used name labels as reminders. The cognitively intact participants told longer stories about themselves, and the facilitators did not need to intervene because they spontaneously posed questions to each other.

The facilitators retrieved the participants' pre-group expectations from the interviews. During the first group meeting, they made them 'real' and visible by reading them aloud anonymously. This was intentional, because some of the participants had reported feeling invisible in the facilities [5]. The participants' responses to this client-centred approach were 
positive. Previous group facilitation, especially among people with cognitive decline, has somewhat lacked a resident-centred focus, which has been criticised [18].

Having the group rules in the form of a contract was important in both groups. The contract was given the analogy of 'a good group recipe' and answered the question, 'Which things should be taken into account so that we have a good, safe team spirit in the group?' However, we observed that the discussion about the good group recipe was facilitator-led in the cognitively impaired group. The participants did not produce many of their own perspectives. The facilitator reflected: 'We had to play an active role in forming the group recipe. We must return to this issue again in the next meeting with the group'. Interaction was more between the facilitator and member rather than the desired member-member interaction [38], in some minor moments there was even facilitator-facilitator interaction. The facilitators' tempo was quite fast: they did not allow enough time for replies or comments on the contract. One facilitator reflected: 'Our role might have been too active due to our assumption that the group participants are not always capable of answering. I have a strong feeling that I will have to trust the group more in the future.' According to Ward et al. [47], letting go of the directive approach is challenging for many facilitators, especially when dealing with people with dementia.

In the initial phase, both groups started with role searching and group formation. For example, in the cognitively impaired group, some participants were active and verbally skilful, even dominant, and others retiring. The facilitators reflected on the experiences of the first meetings: 'Next time we'll divide the participants into pairs in the discussions, it may encourage some of them'. Issues of confidentiality also emerged: could the group be trusted, participants pondered [44]. The cognitively intact group wanted to also raise this theme in the good group recipe. The participants pointed out that a small group is conducive for 
confidence: 'Here you dare to speak openly. It was agreed that this is a closed group. When things come up, they stay inside this group. They don't spread.'

A good team spirit needs a common purpose $[38,48]$. However, according to these two groups it was also important to name the team for good team spirit. A kind of team spirit began to form from the beginning. The participants mutually named their group according to its mood and their humorous exchange of words. The facilitator in the cognitively intact group noted: 'During the coffee break, the group decided to name themselves the "Foxgirls' '('Kettu' is 'fox' in Finnish, but the word can be made into a verb, ketuttaa, or kettuilla, which in turn means to be miffed/annoyed or to make wise cracks/pull someone's leg. A 'fox girl' is also a young female animal rights activist). The group discussed the name without any facilitator intervention:

P6: So are we the Fox girls?

P1: We're a group of fox girls.

P5: Are you feeling miffed (ketuttaa) [laughs]?

P6: Lucky for us this is a closed group and nothing leaks out.

P1: Otherwise they'd be saying in the corridors, here come the fox girls.

P6: Fox girls is perfect. Feels very youthful.

P5: Feels good. Fox girls.

The respective name of the cognitively impaired group was the 'Owl group' (pöllöryhmä). In Finland the owl is a symbol of wisdom but can also refer to a scatty person. The group members promised to hoot to each other outside of the group in their own secret language. In Finnish, in addition to the noise an owl makes, 'to hoot' can mean to beckon someone.

Creating a group name and the cooperation this entailed promoted a huge leap towards group cohesion: the participants had a common mission and a mutual connection [19]. In both groups, the participants seemed to creatively use their resources to find and achieve a team spirit. 
In the cognitively impaired group, the participants had some difficulties keeping up with some of the topics of the meetings. For example, 'biographical stories of one's life' was too abstract for them, especially for one person in the group who was occasionally disoriented. The intensity and methods for facilitating a group depends a great deal on the group dynamics and the abilities of the participants [46]. The facilitators concretised the topic of biographical stories using a map of Finland. The participants were able to draw their biography on the map: where they had been born and where they had lived, where important things had happened to them, etc. The facilitator reflected: 'With the help of the map and our questions, the participants told us about finding their spouses, having children, moving to different places. They reminisced about old times. One shy participant in particular started to talk and really shone'. This kind of task should be performed gradually, step by step, until the best way is found to suit the participants' functional abilities. Thus, participants should not be underestimated. Even the most disoriented participants could relate their biographies, and when doing so were treated with respect and dignity [38].

Both groups expressed feelings of loneliness with the aid of 'Images of loneliness' [45], a method which is based on the idea that loneliness can be visualised using art pictures. Loneliness may have many different 'shapes' in participants' minds. Pictures may stimulate them to reflect on loneliness $[5,45]$. Using this method, the facilitators divided the group participants into pairs. Then they gave each pair 5-10 postcards, art pictures, mostly painted by familiar Finnish artists. The pairs had to pick one card which best described loneliness in their shared opinion. The facilitator described how in the cognitively impaired group: 'I invited the participants to discuss the cards with their partners and to pick a card together that somehow represented the feeling of loneliness. One participant could not do the task, she just sat holding the cards in her hands. Then, her partner began to help her. This made me realise how many different skills the group participants have together.' Participants may best 
promote their shared agency through co-operation. This reciprocal relationship may also have promoted their connectedness in this task [49].

\section{The middle phase: towards effective group intervention through minor conflicts and tiredness}

Toseland [38] notes that as participants become adjusted to the group, their energy is freed for common work and achieving its goals. In these groups, however, it was essential to also work through minor conflicts and feelings of tiredness towards effective group functioning and later self-directedness. The most common conflict was related to the participants' absence from the group and the difficulties in gathering together the participants before group meetings. The participants were very frail, especially in the cognitively intact group. They had many serious illnesses and mobility problems. Because the group facilitators were not members of staff and did not have access to every department, the facilities' assistive nurses and social instructor were supposed to help the participants get to the club room whenever they needed help. This was not always successful.

Maizler \& Solomon [27] noted that group facilitators should not take anything for granted on the part of staff. Making sure that all the participants are present requires co-ordination and pre-group activity on the part of the facilitators [27]. For example, one facilitator reflected irritably after the fifth group meeting of the cognitive impaired group: 'The nurses didn't bring anyone. We brought them from different places. From the gym, from the dining room and from their own rooms'. However, these problems of gathering together the participants also seemed to create an opportunity for the group to interact freely in the club room while the group facilitators sought the missing participants. The observer noted in the middle phase: 'When the group members arrived one by one in the club room, they greeted each other 
warmly and started to talk in turns about coffee making, weather and their aches and pains, while others listened. One of them wondered curiously about how the coffee maker worked, but did not dare to put it on'. This observation enabled us to notice that the participants were sharing something unique in this moment. Even in cognitive decline, they were able to use and benefit from reflective, free space for interaction, which may have reinforced their sense of identity and belonging [47].

When a participant was absent from the group, those who were present made a common handgesture greeting to the absentee, supported by the facilitators. This was an important coping strategy to handle absences. 'If one of the participants is not present, they are still present in our thoughts and visible in our greetings. They are remembered, involved', the facilitator reflected. When someone was missing, it was deliberately commented on. At the same time, this proved to the group that everyone has a place, everyone belongs, and someone is expecting them, even if they are not present [49]. One of the participants told us: 'If someone is sick or absent for some other reason, they send a card. Like friends. They think about a person who is absent, they care'. This strategy seemed to increase the group's confidence and commitment.

However, the free interactions between those in the club room when the facilitators were gathering missing participants, could also create tension or minor conflicts. One participant in the cognitively intact group started relating some childhood memories, including how sheep were slaughtered in the countryside. This caused one member to feel nauseous, and they became angry and left the room. The staff of the assisted living facility also caused surprising conflicts in both groups: one or several members of the staff came to the club room during the group meetings, regardless of the 'Please do not disturb' sign attached to the door. They neither asked for permission to interrupt nor apologised for the interruption. 
Bad moods, pain and the need to go to the bathroom were the reasons in the cognitively impaired group for a person leaving prematurely or not participating at all in the meetings. In both groups, the participants also became tired, although not often. One facilitator reflected: 'I interpreted her body language and knew she'd leave, her presence seemed somehow tired and painful'. One of the cognitively impaired participants said she was 'going home' during the group meeting. According to Cooney [50], such 'going home' talk may relate to experiences of loneliness. Going to the bathroom or pain did not affect presence so often in the cognitively intact group. In contrast, one participant said: 'I feel more pain when I'm alone in my room. In this group my pain can be forgotten'.

Two participants in the cognitively intact group had poor commitment. One of them dropped out after the sixth group meeting. She argued: 'I feel I have nothing to tell the group and there's no one to make friends with'. The other was absent from four meetings. This person was the youngest. She strongly criticised the older participants for having an overly simplistic understanding of loneliness, and felt that she herself was above this: 'Oldies are used to thinking that loneliness is only bad and friendship is good. I think the residents here belong to a different age group to me. When I saw the people here, I felt immediately that I have nothing in common with these grannies'. For her, not showing up at a meeting may have represented an unconscious or intentional excuse to avoid talking about her painful experiences of loneliness. Sometimes dealing with losses causes a fear of things becoming worse [19]. However, being several years younger than the other participants, probably did not support the homogeneity of the participants in respect of age [19].

Signs of reciprocal relationships and an effectively working group emerged between the participants during the middle phase. They started to give each other positive feedback. They spontaneously brought sweets to the group meetings. In the cognitively impaired group, the participants started to remember other participants' names and were pleased when they 
remembered the meeting: 'We were here last week too'. The facilitator reflected on the cognitively impaired group: 'Everyone seemed to be happy to see each other'. However, the development of the group process was not linear in either group; it fluctuated. The facilitators' roles also affected this. One of them noted: 'I noticed that I take part in the conversations too actively. I need to empower the participants more to talk to each other. I am so excited about my work that sometimes I forget my duty to step back.'

\section{Final phase: meaningful engagement}

In the ninth group meeting, one man and one woman in the cognitively impaired group came together to the group without needing to be escorted by the staff. In addition to this, they also brought along a third participant. The facilitator reflected: 'They had formed a group, truly. We could see friendship, activity and initiative. Such huge potential!' They cared for their peers, despite their diminished cognitive abilities. Friendship facilitating may have produced shared agency [18]. The person who was interested in coffee making during the middle phase had started to take responsibility for making the coffee. She commented happily: 'For two years I've not been allowed to make coffee in my room, but here I can make it. Oh yes, that's a good smell!' The observer noted how another participant set the table: she put the cups upside down and the plates on the cups. However, this did not disturb the group meeting and the facilitators did not need to intervene. We believe that these occupations of escorting each other, making coffee and setting the table gave the participants access to a meaningful process with others; this promoted their own participation and social identity. Everyday meaningful occupations shared with peers, even among those with cognitive decline, promote belonging and emotional bonds, which may be associated with togetherness and are in contrast with loneliness $[18,49]$. 
The eleventh group meeting of the cognitively impaired group was at a campfire site in which the participants had expressed an interest. The facilitator observed how nice it was to get the group out of the facility and to give them an authentic nature experience: 'I felt that the trip burst the bubble that excluded them from the world. Now they had the opportunity to feel the wind and see the campfire. It was a joy to me'. Earlier research findings [51] have suggested how frail older people living in loneliness can truly be seen as being in a bubble with physical and mental barriers. To participants, getting out may have also represented hope of escaping their loneliness [5].

The five active participants in the cognitively intact group engaged in deep conversations. The discussions were more diverse than those in the cognitively impaired group. The topics arose from the participants' mutual interactions. The facilitator commented: 'The participants talked about even painful topics and some in the group dared to disagree'. Two women openly talked about the difficult times in their lives and noticed that they had similar experiences. In the last phase they wanted to sit next to each other. At the end of the last meetings, the participants were in no hurry to return to their apartments. 'We sat together for 20 extra minutes after the end of the session. We facilitators were completely quiet for that time'. The facilitators deliberately started to make themselves unnecessary and began to facilitate only when needed. This was important to empower the participants in self-direction. Ward [47] also notes the importance of facilitators 'standing back' and supporting rather than leading.

At the end, the cognitively impaired participant who made the coffee for the group spontaneously suggested: 'I'll make the coffee, if we continue the meetings'. The other participants agreed. The facilitator reflected emotionally: 'I had tears in my eyes when a man in the group said that they had become friends. It came from the heart, he seemed to be a person who meant what he said. He had also proudly told the nurse about the group's further 
plans'. In the cognitively intact group, the future plans remained uncertain in some respects. Some participants seemed to feel uncomfortable about taking responsibility for continuing independent meetings. However, in the last group meeting, four participants decided to continue on their own. One participant was not sure if she would be involved: 'But I will consider this over the summer', she said. The facilitator reflected: 'For the future, the group needs only a common time and space, and the frailest people need some help with mobility. Yes, they can do it'.

\section{Independent meetings}

Three months after the facilitated group process, both groups were meeting weekly on their own. These meeting were not completely independent. The cognitively intact participants needed some help from the staff with mobility as well as in implementing the contents of the group meeting that they planned together. However, the participants retained the decisionmaking power. The cognitively impaired group, in turn, needed a reminder to assemble the group. One member of the staff was active in this. However, this member of staff also started to lead the group meetings, and it seemed that the empowerment and shared agency that the group participants had achieved together during the original group process, partially evaporated with the new staff facilitator. This is a reminder of how crucial it is that the staff empower the participants and support their resources. This member of the staff may not have had this expertise.

\section{Discussion and conclusion}

Studies exploring group interventions among lonely residents in assisted living facilities are scarce. To our knowledge, this is the first study to thoroughly explore the group process among very frail and/or cognitively impaired lonely older people in an institutional setting. 
The novelty of this intervention lies in trusting these frail, older people's capabilities of making new friends and empowering them to help themselves and their peers. In this context, their group process surprisingly resembled that of healthier community-dwelling older people [27]. Using our rich data, we examined and described the group process among residents both with and without cognitive impairment who suffered from loneliness in long-term care facilities. This provided novel, important information for those who design group interventions in institutional settings.

Lonely residents in two assisted living facilities took part in a closed occupational therapyoriented group process which lasted three months. The cognitively impaired and cognitively intact group took similar and parallel steps, from which the participants seemed to benefit. Surprisingly, the cognitively impaired group took these steps in a self-directed group even sooner than the cognitively intact group. The participants had deep group discussions in the cognitively intact group and both groups had a great deal of mutual interaction. Everyday meaningful occupations shared with peers played an essential role in the progress of the group process.

The participants' individual interviews in the planning phase were important in smoothing out and clarifying the start of the group process. Making the participants' expectations visible was essential. In line with previous studies, facilitating the group phases from the planning to the final phase using a resident-centred focus as well as reflecting on the attenuating role of the facilitator empowered the participants and encouraged them towards self-direction. Nonetheless, there were some reciprocating movements in the group stages in relation to the phases. Minor conflicts forced the facilitators to consider methods for keeping everyone involved in the process. 
Arranging independent meetings after the facilitated process was somewhat challenging. This may due to the participants' mobility problems as well as their impaired cognition. Thus, the support of the staff could have been more empowering. However, the success of the group process up until the independent meetings, especially among the cognitively impaired residents, was a surprise to us. The meetings after the facilitated process seemed to be meaningful to the participants.

These findings confirm our understanding of how living in assisted facilities does not reduce the fundamental human need to feel visible, acknowledged and connected to others. In our study, the mutual interaction and self-direction created in both groups revealed the extent of the resources and capacity of lonely residents in assisted living facilities, despite their frailty and cognitive impairment. We suggest that lonely residents' capabilities to make new friends and help themselves in a group should be taken into account in assisted living facilities.

Facilitated groups should be encouraged in the long-term care settings. Occupational therapy practitioners should consider the group process a part of their work focusing on experiences of loneliness in assisted living facilities in co-operation with other elderly care professionals.

\section{Table 3. Recommendations for facilitating older people's group meetings in institutional settings}

Interview participants individually before the meetings: ask about their experiences of loneliness and their expectations of the group meetings.

Create a secure group structure. Ask group participants: "What is your recipe for a good group spirit".

When the meeting starts, discuss the goals of each participant as well as the common goals of the group.

Take enough time to let participants become acquainted within their group - do not assume that they already know each other, even if they live as neighbours.

Facilitate discussions about loneliness: use pictures of art or nature, for example. 
Empower older people to help themselves and their peers.

Facilitate meaningful activities, emphasize the participants' own interests.

Facilitators should work as pairs to be able to reflect on their experiences of group meetings together.

Observations of group stages, phenomena and group dynamics are helpful in understanding the group process.

Participants benefit from positive feedback.

Facilitators should gradually make themselves unnecessary in the meetings and step aside when it is time.

\section{Methodological considerations}

One limitation of this study is that it explores only two small groups in respect to their group processes. Thus, it cannot be generalized to other groups in these settings. We observed that participants in these two groups received the 'right mix of contents' of the intervention. However, we don't know how much variability is needed in the group process for example in other settings [37]. Furthermore, it is only descriptive exploration of the group model in a specific context and it did not include follow-up of these groups. Thus, we cannot conclude whether it has similar effects as the original model [29].

However, it seems that the group model works well in assisted living facilities and in line with the original [27], also among frail and cognitively impaired older people. This was a key question in exploring a feasibility of a complex intervention: whether the Circle of Friends model originally designed for community-dwelling older people fits in different context. Feasibility study may have been an essential step before further studies, for example when evaluating the process of implementation and dissemination of the intervention in these settings. In order to reproducibility in the future, we carried out a full description of the 
intervention, which hopefully helps social and health care professionals and researchers to understand of its process and adopt the model for successful implementation [37].

The Circle of Friends group model chosen for the study is an occupational therapy-oriented, closed group rehabilitation model, originally designed in a randomised, controlled trial for community-living older people suffering from loneliness. Many Circle of Friends trainers in Finland are occupational therapists, as were the trainers of the facilitators of this study. The training model is described in detail elsewhere [28].

\section{Acknowledgements}

We thank the Olvi Foundation (grant number 201810048), the Orion Research Foundation (grant number 180044), the Signe and Ane Gyllenberg Foundation (no grant number available), and the Miina Sillanpää foundation (no grant number available) for the funding for this study. The funding sources played no role in the design or conduct of the study; in the collection, analysis or interpretation of the data; nor in the preparation, review, or approval of the manuscript. This research was approved by the Helsinki University Hospital ethics committee (1150/2016) and the committee of Helsinki City (2016-014058). The first author, Anu Jansson (AJ), is an occupational therapist and conducted the recruitment of the participants, made the group arrangements, and collected the data. Each writer played an equal role in writing the manuscript.

\section{Declaration of interest}

The authors report no conflicts of interest. 


\section{References}

1. Victor C. Loneliness in care homes: a neglected area of research? Aging Health. 2012;8(6):637-646

2. Prieto-Flores ME, Fernandez-Mayoralas G, Forjaz MJ et al. Residential satisfaction, sense of belonging and loneliness among older adults living in the community and in care facilities. Health Place. 2011;17(6):1183-90.

3. Sletteb $₫$ A. Safe, but lonely: Living in a nursing home. Vard Nord Utveckl Forsk. 2008;87(28):22-25.

4. Theurer K, Wister A, Sixsmith A, et al. The Development and Evaluation of Mutual Support Groups in Long-Term Care Homes. J Appl Gerontol. 2014;33(4):387-415.

5. Jansson A, Karisto A, Pitkälä K. Time- and place-dependent experiences of loneliness in assisted living facilities. Ageing Soc. Forthcoming. [cited 2019 May 16]

6. Savikko N, Routasalo P, Tilvis RS, et al. Predictors and subjective causes of loneliness in an aged population. Arch Gerontol Geriatr. 2005;41:223-233.

7. Bekhet AK, Zauszniewski JA. 2012. Mental health of elders in retirement communities: Is loneliness a key factor? Arch Psychiatr Nurs. 2012;26(3):214-224.

8. Jansson AH, Muurinen S, Savikko N, et al. Loneliness in nursing homes and assisted living facilities: prevalence, associated factors and prognosis. J Nurs Home Res Sci. 2017;3:43-49.

9. Tilvis RS, Pitkälä KH, Jolkkonen J, et al. Social networks and dementia. Lancet. 2000;356:76-8.

10. Luanaigh CO, Lawlor BA. Loneliness and the health of older people. Int J Geriatr Psychiatry. 2008;23:1213-1221.

11. Hawckley LC, Cacioppo JT. Loneliness Matters: A Theoretical and Empirical Review of Consequences and mechanisms. Ann Behav Med. 2010;40: 218-227

12. Cacioppo JT, Hawkley LC, Norman GJ, et al. Social isolation. Ann N Y Acad Sci. 2011;1231:17-22.

13. Tilvis RS, Routasalo P, Karppinen H, et al. Social isolation, social activity and loneliness as survival indicators in old age; a nationwide survey with a 7-year follow-up. Eur Geriatr Med. 2011;3:18-22.

14. Drageset J, Eide GE, Kirkevold M, et al. Emotional loneliness is associated with mortality among mentally intact nursing home residents with and without cancer: a five-year follow-up study. J Clin Nurs. 2012;44,106-114.

15. Roth EG, Eckert JK. The vernacular landscape of assisted living. J Aging Stud. 2011;25:215-224.

16. Bergland A, Kirkevold M. The significance of peer relationships to thriving in nursing homes. J Clin Nurs. 2008;May;17(10):1295-302.

17. Bradshaw S, Playford D, Riazi A. Living well in care homes: A systematic review of qualitative studies. Age Ageing. 2012;41(4):429-440. 
18. Theurer, K, Mortenson WB, Stone R, et al. The need for a social revolution in residential care. J Aging Stud. 2015;35:201-210.

19. Agronin M. Group therapy in older adults. Curr Psychiatry Rep. 2009;11(1):27-32.

20. Smallfield S, Molitor WL. Occupational Therapy Interventions Supporting Social Participation and Leisure Engagement for Community-Dwelling Older Adults: A Systematic Review. Am J Occup Ther. 2018;72(4)

21. Safford F. Group work in Long-Term Care Facilities. In: Burnside I, Schmidt MG. Working with older adults. Group Process and techniques. Third Edition. Jones and Barlett Publishers. Sudbury, Massachusetts; 1994. p. 227-239.

22. Lowy L. The Group in Social Work with the Aged. Soc Work.1962;7(4):43-50

23. Maizler JS, Solomon JR. Therapeutic Group Process with the Institutional Elderly. J Am Geriatr Soc. 1976;24:542-546.

24. Cattan M, White M, Bond J, et al. Preventing social isolation and loneliness among older people: a systematic review of health promotion interventions. Ageing Soc. 2005;25:41-67.

25. Cohen-Mansfield J, Perach R. Interventions for Alleviating Loneliness Among Older Persons: A Critical Review. Am J Health Promot. 2014;29,3:109-125.

26. Winningham RG, Pike NL. A cognitive intervention to enhance institutionalized older adults' social support networks and decrease loneliness. Aging Ment Health.

2007;11(6):716-721.

27. Pitkälä KH, Savikko N, Routasalo P. Group Dynamics in Older People's Closed Groups: findings from Finnish psychosocial group rehabilitation for lonely older people. In Derrickson H, Group Therapy. Nova Science Publishers, 2015. p. 39-73

28. Jansson AH, Savikko N, Pitkälä KH. Training professionals to implement a group model for alleviating loneliness among older people - 10-year follow-up study. Educ Gerontol. 2018;44:2-3:119-127

29. Pitkälä KH, Routasalo P, Kautiainen H, et al. Effects of Psychosocial Group Rehabilitation on Health, Use of Health Care Services, and Mortality of Older Persons Suffering From Loneliness: A Randomized, Controlled Trial. J. Gerontol. 2009;64:792-800.

30. Laakkonen ML, Kautiainen H, Hölttä E, et al. Effects of Self-Management Groups for People with Dementia and Their Spouses--Randomized Controlled Trial. J Am Geriatr Soc. 2016;64(4):752-60.

31. VTKL.fi [Internet] Helsinki, Finland: Vanhustyön keskusliitto; [cited 2019 May 2] Available from: www.vtkl.fi/ystavapiiri-toiminta

32. Zimmerman S, Sloane PD, Reed D. Dementia prevalence and care in assisted living. Health Aff. (Millwood). 2014;Apr;33(4):658-66

33. Clare L, Rowlands J, Bruce E, et al. The Experience of Living With Dementia in Residential Care: An Interpretative Phenomenological Analysis. Gerontologist. 2008;48,6:711-720.

34. Payne KT, Marcus DK. The efficacy of group psychotherapy for older adult clients: A meta-analysis. Group Dyn. 2008;12(4),268-278. 
35. Folstein MF, Folstein SE, McHugh PR. "Mini-Mental state": a practical method of grading the cognitive state of patients for the clinician. J Psychiatr Res. 1975;12:189-98.

36. Savikko N. 2008. Loneliness of older people and elements of an intervention for its alleviation. [dissertation] Turku, Finland: University of Turku; 2008.

37. Craig, Peter \& Dieppe, Paul \& Macintyre, Sally \& Michie, Susan \& Nazareth, Irwin \& Petticrew, M. 2019. Developing and evaluating complex interventions: Following considerable development in the field since 2006, new guidance. Medical Research Council. 1-39. https://mrc.ukri.org/documents/pdf/complex-interventions-guidance/

38. Toseland RW. Group work with older adults. New York University Press. New York and London, 1990.

39. Tuckman BW. Developmental sequence in small groups. Psychol Bull. 1965;63:384-99.

40. Findlay RA. Interventions to reduce social isolation amongst older people: where is the evidence? Ageing Soc. 2003;23:647-658.

41. Burnside I. Group Goals and Contracts: Assessment and Planning. In: Burnside I, Schmidt MG. Working with older adults. Group process and techniques. Third Edition. Jones and Barlett Publishers. Sudbury, Massachusetts, 1994. p. 75-81.

42. Graneheim UH, Lundman B. Qualitative content analysis in nursing research: Concepts, procedures and measures to achieve trustworthiness. Nurse Education Today, 2004;24:105112.

43. Craig P, Dieppe P, Macintyre S, Michie S, Nazareth I, Petticrew M. Developing and evaluating complex interventions: the new Medical Research Council guidance. BMJ, 2008;337:a1655

44. Evans S, Chisholm P, Walshe J. A dynamic psychotherapy group for the elderly. Group Anal. 2001;34,2:287-298.

45. Blomqvist L, Pitkälä K, Routasalo P. Images of loneliness: using art as an educational method in professional training. J Contin Educ Nurs. 2007;38:89-93.

46. Goldsilver PM, Gruneir MR. Early stage dementia group: an innovative model of support for individuals in the early stages of dementia. Am J Alzheimers Dis Other Demen.

2001;16(2):109-14.

47. Ward R, Howorth M, Wilkinson H, et al. Supporting the friendships of people with dementia. Dementia. 2011;11,3:287-303.

48. Bion WR. Experiences in groups and other papers. Routledge. London and New York, 1961.

49. Nyman A, Josephsson S, Isaksson G. Being part of an unfolding story: togetherness in everyday occupations when ageing. Scand J Occup Ther. 2014;21(5):368-76.

50. Cooney A.'Finding home': a grounded theory on how older people 'find home' in longterm care settings. Int J Older People Nurs. 2012;7:188-199. 
51. Taube E, Jakobsson U, Midlöv P. et al. Being in a Bubble: the experience of loneliness among frail older people. J Adv Nurs. 2016;72,3:631-40 